\title{
KEBUTUHAN MODEL BUDAYA PELA GANDONG BERBASIS PEMBANGUNAN DI PROVINSI MALUKU
}

\author{
I.H. Wenno dan Wilma Akihary
}

Email: wennoiz@yahoo.co.id,wilamq@yahoo.com

FKIP Universitas Pattimura Ambon

Alamat Korepondensi: Jalan Ir. Putuhena Kampus Poka Ambon 97233

\begin{abstract}
Pela Gandong is one of traditions in Maluku based on relation between people of one area to the people in another place that can't be dismissed by anyone. This topic is interesting remembering the important role the Pela Gandong has. This paper aims to find out a a guidance or models of Pela Gandong based on character building. It is very useful to develop culture education in Maluku province. The result of this research can help goverment to increase social culture and harmony of people, as well as teacher and lecturer in their learning process. Method used in this research was research and development models developed by Borg and Gall with some step i.e. survey, planning for model will be developed, product try out, product developing, product validation, socialitation, and product implementation. The first step of this reserch is a preliminary study conducted to know general perception of people about Pela Gandong through descriptive qualitative approach. The population of this research is all people in Central Maluku province, while sample used in this research were 50 villages. Instruments used were questionaire and interview. Data are collected and analyzed using qualitative approach. The result shows that Pela Gandong is a tradition that can be developed as a means to built characters and education of people that will further contribute to the national development.
\end{abstract}

\section{Keywords}

Pela Gandong, Budaya, Maluku

\section{Pendahuluan}

Indonesia adalah negara dengan wilayah yang memiliki karakteristik geografis yang sebagian besarnya adalah laut. kondisi ini mengakibatkan terjadinya keanekaragaman budaya masingmasing kelompok masyarakat. Tidak dapat dipungkiri bahwa keanekaragaman budaya ini terkadang membawa masyarakat pada konflik. Sehingga, tidak mengherankan bila pada beberapa tahun terakhir terjadi konflik di beberapa wilayah di Indonesia. Misalnya, konflik di Kalimantan yang melibatkan etnis Dayak dan Madura, konflik Poso, konlfik Ambon yang bernuansa SARA, maupun konflik antar suku di Papua.

Pemerintah dengan segala daya dan upaya mencoba melakukan berbagai cara untuk dapat menghentikan konflik meski pada kenyataannya masih kurang berhasil bahkan jauh dari apa yang diharapkan. Belajar dari konflik kemanusiaan yang bernuansa SARA pada tahun 1999-2004 yang terjadi di Maluku, dapat diambil salah satu contoh nilai kearifan lokal yang berkembang di
Maluku khususnya Maluku Tengah yaitu budaya Pela dan Gandong.

Kebudayaan pada dasarnya mucul sebagai respon manusia terhadap segala tantangan yang dihadapi dalam kehidupan. Seperti yang dikemukakan oleh Koentjaraningrat bahwa kebudayaan merupakan keseluruhan gagasan, tindakan dan hasil karya manusia dalam rangka kehidupan yang dijadikan milik diri manusia dengan belajar (1984:180). Teori yang digunakan dalam penulisan ini yaitu Teori Fungsionalisme Struktural Talcot Parsons, yaitu bahwa masyarakat terintegrasi atas dasar kesepakatan para anggotanya akan nilai-nilai kemasyarakatan tertentu yang mempunyai kemampuan mengatasi perbedaan-perbedaan sehingga masyarakat tersebut dipandang sebagai suatu sistem yang secara fungsional terintegrasi dalam suatu keseimbangan. Dengan demikian, masyarakat adalah merupakan kumpulan sistem-sistem sosial yang satu sama lain berhubungan, dan saling ketergantungan. Teori lain yang digunakan yaitu teori fungsionalisme universal. Robert Merton menyatakan bahwa seluruh bentuk 
sosial dan bentuk kebudayaan yang sudah baku memiliki fungsi positif. Berkaitan dengan hal yang telah disampaikan di atas, maka budaya Pela Gandong memiliki nilai positif dalam proses kehidupan masyarakat di Maluku Tengah.

Budaya Pela Gandong merupakan identitas diri dari masyarakat di Maluku Tengah yang hadir sebagai wujud integrasi kehidupan masyarakat yang pada awalnya diliputi perang antar suku kemudian berubah menjadi hubungan persaudaraan yang erat seperti layaknya saudara kandung. Hubungan ini terjalin tanpa melihat latar belakang perbedaan agama, suku, ras, dan lainnya.

Pada tahun 1999-2004 terjadi konflik bernuansa SARA. Saat itu eksisitensi budaya Pela Gandong dipertanyakan. Ada yang memprediksi untuk mencapai tahapan perdamaian akan memakan waktu puluhan tahun. Berkembang juga pikiran bahwa Pela Gandong tidak lagi diperlukan karena bertentangan dengan nilai-nilai agama. Bahkan, ada ide untuk memisahkan masyarakat melalui relokasi pemukiman. Tetapi, tercatat bahwa apa yang diperkirakan keliru. Kesadaran masyarakat tentang pentingnya Pela Gandong justru menjadi salah satu indikator perdamaian konflik.

Sebagai wujud untuk mempererat hubungan ini oleh masyarakat dilakukan Panas Pela. Tetapi jika diperhatikan, ada kesan bahwa yang dilakukan ini sebagai kegiatan menghambur-hamburkan uang sesaat yang tidak ada manfaatnya. Dengan demikian perlu dilakukan suatu terobosan untuk dapat merubah pola yang dilakukan dengan cara yang lebih bermanfaat, dan berguna. Terobosan yang ditawarkan dalam penelitian ini yaitu bagaimana menjadikan budaya Pela Gandong sebagai basis dalam proses pembangunan.

Pela Gandong merupakan kearifan lokal yang dijunjung tinggi oleh masyarakat sebagai bentuk hubungan kerja sama saling menguntungkan diantara masyarakat tanpa melihat latar belakang perbedaan suku, agama, ras dan sebagainya. Hubungan pela dan gandong merupakan jati diri masyarakat pendukungnya, hal ini dapat dilihat dalam kehidupan yang saling mengasihi, tolong menolong layaknya saudara (adik dan kakak). Dapat dikatakan bahwa karena kesadaran masyarakat terhadap pentingnya pela dan gandong sebagai warisan budaya para leluhur, maka konflik Maluku dapat sampai pada tahapan rekonsiliasi dan perdamaian dalam jangka waktu yang sangat singkat.

Pada kenyataannya untuk mempererat hubungan Pela Gandong di antara negeri yang memiliki hubungan pela, maka dilakukan upacara Panas
Pela. Acara ini dilakukan sesuai dengan kesepakatan di antara negeri yang berpela, baik jangka waktunya maupun tempat pelaksanannya. Dalam acara ini akan diceritakan kembali hal ihwal terjadinya hubungan pela antara negeri yang melaksanakannya. Hal itu dimaksudkan sebagai sarana untuk mewariskan nilai- nilai kearifan dari para leluhur kepada generasi muda agar mereka mengetahui dan mengikuti segala janji, dan sumpah yang mengikat mereka. Pelaksanaan panas pela dilakukan melalui persiapan yang sangat lama minimal lima tahun, dan membutuhkan biaya yang sangat besar. Hal ini terkadang menjadi beban bagi anggota masyarakat

Jika mencermati realitas di atas, sebaiknya harus dapat dilakukan hal yang lebih penting dan berguna bagi generasi sekarang daripada sekedar kumpul, bercengkrama, bersenang-senang sesaat tanpa ada hasil yang berarti bagi masyarakat.

Harus ada pencegahan terhadap konflik karena pola hidup manusia saat ini telah mengalami pergeseran dan lebih cenderung ke arah individualistis dan materialistis. Semua itu harus bisa diimbangi tawaran solusi dengan cara menjadikan masa lampau sebagai sarana untuk membangun masyarakat ke arah yang lebih baik. Jika hubungan pola awal terjadi karena saling membantu dalam hal perang maupun bantuan lainnya, maka hal yang harus dilakukan sekarang adalah bagaimana model ini dikembangkan sesuai dengan perkembangan zaman tanpa meninggalkan nilai historisnya sehingga dapat menjadi model penerapan pembangunan di Indonesia yang harmonis dan penuh toleransi. Pela Gandong sudah saatnya tidak lagi menjadi sesuatu yang ekslusif di antara negeri-negeri yang berpela, tetapi harus diwariskan kepada generasi muda khususnya para siswa dan mahasiswa dengan memasukannya sebagai salah satu bagian muatan lokal pada kurikulum sekolah.

Ikatan Pela Gandong sebagai warisan budaya yang positif harus dipertahankan dan dikembangkan sesuai dengan perkembangan zaman demi kebaikan seluruh lapisan masyarakat sehingga kehidupan masyarakat yang harmonis dapat terwujud.

\section{Metode}

Penelitian ini merupakan jenis penelitian dan pengembangan (R\&D). Adapun model yang digunakan adaptasi model yang dikembangkan oleh Borg \& Gall (1983: 72). Artinya penelitian ini mengikuti langkah-langkah penelitian dan pengembangan. Prosedur penelitian adalah: (1) 
survei pendahuluan, (2) merencanakan model yang akan dikembangkan, (3) mengadakan uji coba produk; (4) mengembangkan produk, (5) validasi produk, dan (6) sosialisasi dan implementasi hasil penelitian (produk).

Tahap studi pendahuluan dilakukan dengan menerapkan pendekatan deskriptif kuantitatif. Yang menjadi populasi dalam penelitian ini adalah seluruh warga masyarakat di Kabupaten Maluku Tengah Propinsi Maluku dengan fokus penelitian terletak pada pembentukan suatu produk budaya pela dan gandong berbasis pembangunan. Sedangkan sampel penelitian adalah 50 Desa di Kabupaten Mauku Tengah. Sumber data diperoleh melalui hasil analisis kebutuhan.

Instrumen penelitian adalah berbagai kuisioner dan daftar wawancara untuk mengetahui pendapat masyarakat tentang hubungan Pela Gandong, kegiatan-kegiatan keharmoniasan antar umat beragama, karakter masyarakat berpela, dan muatan-muatan lokal yang diterapkan di sekolah-sekolah pada daerah-daerah berpela. Pengumpulan data dilakukan melalui studi literatur, angket, studi dokumentasi, interview, dan observasi, sedangkan analisis berupa analisis kualitatif.

\section{Diskusi dan Temuan}

\section{Gambaran Umum Provinsi Maluku}

Secara administratif, Provinsi Maluku terbagi atas 9 Kabupaten dan 1 Kota, 64 Kecamatan, 1034 Desa dan 30 Kelurahan. Secara rinci banyaknya Kecamatan, Desa dan Kelurahan per Kabupaten atau Kota di Provinsi Maluku dapat dilihat pada tabel 1.

Tabel 1. Banyaknya Kecamatan, Desa dan Kelurahan per Kabupaten/Kota di Provinsi Maluku

\begin{tabular}{|l|c|c|c|}
\hline Kabupaten/Kota & Kec & Desa & Kel \\
\hline 1. Maluku Tengah & 11 & 156 & 6 \\
2. Maluku Tenggara & 5 & 110 & 4 \\
3. Pulau Buru & 10 & 94 & - \\
4. Maluku Tenggara & 11 & 118 & - \\
Barat & 3 & 119 & - \\
5. Kepulauan Aru & 4 & 87 & - \\
6. Seram Bagian Barat & 4 & 53 & - \\
7. Seram Bagian Timur & 5 & 30 & 20 \\
8. Kota Ambon & 3 & 53 & \\
9. Buru Selatan & 4 & 38 & \\
10. Maluku Barat Daya & & & \\
\hline Provinsi Maluku & $\mathbf{6 4}$ & $\mathbf{1 0 3 4}$ & $\mathbf{3 0}$ \\
\hline
\end{tabular}

Dengan luas wilayah Provinsi Maluku adalah 712.479,69 km² yang terdiri dari 658.294,69 km² wilayah daratan dengan jumlah penduduk
1.313.022 jiwa dengan kepadatan penduduk 24 jiwa per $\mathrm{km}^{2}$. Oleh sebab itu, untuk meningkatkan mutu pendidikan di Provinsi Maluku pemerintah hendaknya melakukan berbagai kebijakan yang dapat menyentuh pembangunan di bidang pendidikan dalam hal ini pembangunan yang bertujuan untuk meningkatkan mutu pendidikan di Provinsi Maluku.

Adanya perubahan sosial dan sektor lain yang berkembang dengan cepat dan dinamis, menimbulkan permasalahan kebijakan yang dinamis. Kenyataan ini membutuhkan adanya kajian yang dapat secara cepat dan tepat merespons perubahan-perubahan yang dinamis tersebut. Respon yang cepat dan tepat diharapkan dapat memberikan masukan bagi penyusunan agenda kebijakan pembangunan yang menyeluruh didasarkan pada potensi budaya di Provinsi Maluku.

Pengkajian sektor budaya adalah suatu kegiatan guna menghasilkan, dan menyajikan informasi untuk memberikan landasan dalam penetapan kebijakan dan arah pembangunan yang didasarkan pada kultur, dan budaya. Agar kebijakan yang ditetapkan dapat secara efektif memecahkan berbagai permasalahan yang ada, perlu disadari pertimbanagan input data dan informasi yang rasional dan matang melalui pengkajian. Dengan kata lain, kebijakan yang efektif adalah kebijakan yang disusun berdasarkan informasi aktual yang relevan dan tepat, bukan atas perkiraan yang belum dicek kebenarannya. Oleh sebab itu, untuk melihat kesenjangan yang terjadi di Provinsi Maluku sebagai daerah kepulauan, pemerintah harus dapat mengembangkan model pendidikan budaya yang berorientasi pada karakteristik wilayah.

\section{Pentingnya Budaya Pela Gandong}

Hasil wawancara terhadap responden, menunjukan bahwa pada prinsipnya masyarakat di Kabupaten Maluku Tengah masih memiliki ikatan persaudaran yang disebut dengan Pela Gandong. Bagi masyarakat, budaya Pela Gandong merupakan hubungan gandong atau adik kakak yang tidak boleh dipisahkan. Jadi maksudnya adalah saudara serahim, adik dan kakak yang mengikat suatu perjanjian untuk saling mengasihi karena sekandung atau seperti saudara kandung. Bagi mereka supaya pela itu tetap hidup dan supaya anak-anak muda disadarkan kewajibannya, maka harus dilakukan suatu upacara 'Bikin Panas Pela'. Pada kesempatan itu semua saudara berkumpul untuk merayakan hubungan persatuannya dengan 
membaharui sumpahnya, bersukacita sambil menyanyi, dan melakukan tari-tarian.

Sistem pela sebagaimana diuraikan di atas ini masih berperan penting di Maluku Tengah karena rasa persatuan dan identitas bersama disadari dan dihayati dengan kuat, upacaraupacara pembaharuan pela masih sering berlangsung. Malah dapat dikatakan bahwa berkat sistem pela itu, pertentangan antara kaum muslimin dan kaum kristen tidak dapat berkembang. Hal ini sangat berlainan dengan keadaan hubungan antara kedua umat beragama itu di tempat lain. Sebagai kenyataan, banyak gedung gereja mesjid dan sekolah sempat dibangun karena bantuan dari pela yang menyumbang tenaga kerja, bahan bangunan, uang atau makanan bagi para pekerja, sehingga usaha-usaha itu dapat terlaksana dengan tiada sumbangan apapun dari pemerintah.

\section{Kehidupan Masyarakat Berpela}

Dari hasil need assesment terhadap 50 Desa di Kabupaten Maluku Tengah, dapat disimpulkan bahwa rata-rata semua desa masih menginginkan budaya Pela Gandong perlu dikembangkan lagi.

Dari hasil observasi terhadap pentingnya budaya Pela Gandong, dapat digambarkan bahwa pada prinsipnya masyarakat Maluku Tengah menganggapnya sebagai hubungan persaudaraan atau perserikatan antara dua negeri (desa) atau lebih yang beragama Islam maupun Kristen. Jika hubungan itu didasarkan pada adanya hubungan darah karena meyakini mereka berasal dari satu keturunan atau datuk/leluhur, maka hubungan itu tetap harus dipertahankan dan tidak boleh dimusnahkan.

Dari hasil analisis kualitatif terhadap observasi yang dilakukan oleh Tim Peneliti terlihat bahwa Ikatan pela dan gandong sebagai warisan budaya yang positif harus dipertahankan dan dikembangkan sesuai dengan perkembangan zaman, demi kebaikan seluruh lapisan masyarakat sehingga kehidupan masyarakat yang harmonis dapat terwujud.

Namun, hal yang terpenting dalam hubungan Pela Gandong adalah menjadikan budaya ini sebagai bentuk hubungan kerja sama yang saling menguntungkan di antara masyarakat tanpa melihat latar belakang perbedaan suku, agama, ras dan sebagainya. Hubungan Pela Gandong merupakan jati diri masyarakat pendukungnya. Hal ini dapat dilihat dalam kehidupan yang saling mengasihi, tolong menolong layaknya saudara (adik dan kakak).

\section{Dampak Implementasi Budaya Pela Gandong}

Akibat dari implementasi budaya Pela Gandong, dampaknya sangat positif, diantaranya: 1) mempererat hubungan persaudaran tanpa melihat perbedaan agama, 2) dapat digunakan sebagai strategi untuk mengurangi potensi konflik, 3) menumbuhkan kesadaran bagi generasi muda, betapa pentingnya budaya Pela, dan Gandong dalam mengisi pembangunan, 4) dijadikan sebagai model pendidikan karakter di Provinsi Maluku, 5) dimasukan sebagai muatan lokal dalam kurikulum sekolah, dan 6) dijadikan sebagai rekomendasi bagi pemerintah dalam mengantisipasi, dan mengatasi berbagai konflik di Indonesia.

\section{Jenis Budaya Pela dan Ganding}

Hasil penelitian awal menunjukkan bahwa budaya Pela Gandong di Kabupaten Maluku Tengah perlu dikembangkan, dan dilestarikan lebih lanjut, karena hubungan pela tersebut merupakan satu sejarah yang tidak boleh dihilangkan.

Berbagai jenis budaya Pela Gandong yang dapat terdeteksi di kembangkan di Kabupaten Maluku Tengah.

Pertama, Pela keras sering disebut "Pela Tuni" artinya pela sejati karena hubungan atau ikatan yang sangat kuat, dan terikat oleh sumpah yang bersifat sakral. Hubungan pela ini terjadi karena situasi yang membahayakan, misalnya perang sehingga kedua klan atau negeri berdamai. Upacara mengangkat sumpah didahului dengan minum darah kedua belah pihak (jari tangan dilukai atau dengan darah binatang tertentu) yang dicampurkan dengan minuman keras tradisional (sopi). Hal ini melambangkan hubungan persaudaraan yang di bangun untuk selama-lamanya. Yang termasuk dalam pela keras adalah yang disebut pela gandong atau sekandung atau yang disebut pela sudara (pela saudara) atau pela adik kaka (pela adik kakak). Pela ini juga sering disebut pela batu karang karena di anggap kokoh seperti batu karang.

Kedua, Pela lunak, ikatan pela ini tidak melalui sumpah, dan tidak ada kewajiban-kewajiban yang harus dipenuhi dengan ketat jenis pela ini sering di beri nama pela tampa siri (tempat sirih) dan terjadi karena hutang budi, sehingga harus ada balas jasa. Pela ini bersifat sosial ekonomi, dan ikatannya dilakukan dengan makan pinang bersama. Larangan perkawinan antar negeri berpela tidak sekeras pela tuni atau pela gandong serta kebiasaan saling membantu atau tolong menolong menjadi kewajiban negeri berpela. 
Selain itu, pela-pela yang lahir di Kabupaten Maluku Tengah kebanyakan bukan saja pela darah, atau pela tampa sirih, namun terbentuknya pela dan gandong di dorong oleh situasi ekonomi yang memburuk. Sebagai akibat dari sebagian besar lahan pertanian mereka beralih fungsi menjadi perkebunan cengkeh. Sagu yang merupakan makanan pokok masyarakat menjadi berkurang, dan sudah mulai sulit didapat. Padahal pohon sagu di pulau Seram Kabupaten Maluku Tengah tumbuh berlimpah. Itulah sebabnya muncul hubungan pela antara negeri tertentu di Ambon dan Lease dengan negeri-negeri yang ada di sekitar pantai di pulau Seram tujuannya yaitu semata-mata untuk mendapatkan sagu karena itu pela semacam ini dinamakan pela barang atau pela perut. Menurut Colley (1961) pela sebagai suatu ikatan atau hubungan persaudaraan antar seluruh penduduk dari dua desa atau lebih berdasarkan adat. "Pela as it is found a present in Mollucan societies, is an institutionalized bond of friendship ar brotherhood between all native residents of two or more village , which bond was esthabilished by the ancestors." Ada juga yang menyatakan bahwa pela sebagai suatu perserikatan atau sistem persahabatan antar beberapa buah kampong atau negeri, "They keystone among several centerpieces, is an intervillage alliance system called Pela, Pela as it exist in Ambon to day, is a system of relationship tying together two or more villages, often of apart an frequently on different island" (Bartels).

Dengan demikian dapat dikatakan bahwa budaya Pela dan Gandong di Kabupaten Maluku Tengah merupakan salah satu bentuk kekeluargaan, dan ikatan persaudaraan yang nilainya tetap kokoh sampai sekarang ialah hubungan Pela. dikalangan kelompok Patasiwa dikenal istilah pela-pela yang berarti tanda symbol atau gambar yang dilukiskan di anggota tubuh dengan pola, dan bentuk yang mempunyai arti atau pesan tertentu, serta merupakan simbol kesatuan dari satu kelompok. Inilah merupakan suatu kenyataan menunjuk pada ikatan persatuan, dan persaudaraan antara dua negeri atau lebih, baik antara negeri negeri Kristen atau negeri Islam maupun antar negeri Islam dengan negeri Kristen.

\section{PENUTUP}

Berdasarkan hasil penelitian awal yang diperolah, maka dapat disimpulkan beberapa hal. Pertama; budaya Pela Gandong merupakan hubungan gandong atau adik kakak yang tidak boleh dipisahkan. Jadi maksudnya adalah saudara serahim, adik dan kakak yang mengikat suatu perjanjian untuk saling mengasihi karena sekandung atau seperti saudara kandung; Kedua, Pela Gandong yang di kembangkan di Kabupaten Maluku Tengah, terdiri dari: pela keras sering disebut pela tuni artinya pela sejati karena hubungan atau ikatan yang sangat kuat, dan terikat oleh sumpah yang bersifat sakral, dan pela lunak, ikatan pela ini tidak melalui sumpah, dan tidak ada kewajiban-kewajiban yang harus dipenuhi dengan ketat jenis pela ini sering di beri nama pela tampa siri (tempat sirih) dan terjadi karena hutang budi, sehingga harus ada balas jasa; Ketiga, dampak dari implemenasi budaya Pela Gandong dapat dijadikan sebagai model pendidikan karakter di Provinsi Maluku, dimasukan sebagai muatan lokal dalam kurikulum sekolah, dan dapat dijadikan sebagai rekomendasi bagi pemerintah dalam mengantisipasi, dan mengatasi berbagai konflik di Indonesia.

Sehubungan dengan hasil penelitian awal yang berhubungan dengan model budaya Pela Gandong, maka peneliti menyarankan agar Pemerintah Kabupaten Maluku Tengah dapat mengembangan budaya Pela Gandong berbasis Pembangunan yang berorientasi pada pembentukan karakter masyarakat dalam meningkatkan taraf hidup yang lebih baik.

\section{DAFTAR PUSTAKA}

Anastasi, Anne and Susana Urbina. 1997. Psychologycal Testing. New Jersey: Prentice-Hall Inc Published by Simon A Schuster/A Viacom Co Upper Saddle River.

Bartels, Dieter. 1977. Guarding the Invisible Mountain: Aliances, religious Syncretism and Among the Ambonesse Christian and Moslems in the Moluccas. PHd Thesis Cornel University.

Cooley. 1961. Althar and throne in Central Moluccas Societies. PHd Thesis. Yale University.

Lokollo. 1997. Seri Budaya Pela Gandong dari pulau Ambon. Ambon: Lembaga Kebudayaan Daerah Maluku, Ambon.

Pattikayhatu, J.A. 2005. Pela dan Gandong di Maluku Tengah. Ambon: FKIP Universitas Pattimura. 
Poloma, Margaret. 2007. Sosiologi Kontemporer. Jakarta: Rajawali Pers.

Reigluth, Charles M. 1983. Instructional Design and Models; an Overview of Therr Current Status. New Jersey : Lawrence Erlbaun Associates publisher.

Suhartono, W. Pranoto. 2010. Teori \& Metodologi Sejarah. Jakrta: Graha Ilmu.

Wlyam, Douglas M. 1988. Indicators of Educational Effectiviness and Efficiency. USAID 